\title{
Pengaruh Persepsi Konsumen terhadap Keputusan Pembelian Ulang pada Indomaret Kecamatan Sungai Bahar
}

\author{
Wiyan Mailindra', Muhammad Amali ${ }^{2}$ \\ STIE GK Muara Bulian ${ }^{1}$, Fakultas Ekonomi Universitas Batanghari ${ }^{2}$
}

\begin{abstract}
Retail business in Indonesia can be difided into 2 major groups, namely Tradisional Retail and Modern Retail. Modern retail is developed from tradisional retail. This retail format emerged and developed along with economic development, technology, and society life style which make the society demand more pleasure in doing shopping. Along with retail business development, nowadays retail business has not longer managed tradisionally, but in modern ways, therefore it becomes inovative, dynamic, and compatitive business. This research used primer and secunder data, in which primer data were obtained through interview and distributing questionare to 80 respondents, meanwhile secunder data where gotten from literature or document related to this research and were grouped into 2 variables, namely dependent variable and independent variabel, in which repurchase decision as dependent variable and consumen perception as independent variable. The result of this research is consumen perception towards repurchase decision showed by the value $t_{\text {hitung }}$ is 7,563 . With significant value is $0,000<\alpha=0,05$. Therefore it can be said that there is significant effect of consumen perception toward repurchase decision at indomaret. Then it is seen from the value of $t_{\text {hitung }}$ above and compared to value of $t_{\text {tabel. }}$. To get the value of $t_{\text {tabel, }}$, wo ways test was done $d k=n-2$ and $d k=80-2$ $=78$, if deviation degree is determined 0,05 (5\%), so $t_{\text {tabel }}=1,665$. Because the value of thitung $>t_{\text {tabel }}$ it means that Ha is accepted and Ho is rejected. It means that there is significant effect of consumen perception toward repurchase decision at indomaret.
\end{abstract}

Keyword: Retail business, Consumen perception.

\section{PENDAHULUAN}

Setiap perusahaan dituntut untuk menciptakan strategi bersaing yang baik dan terpadu karena persaingan adalah kunci dari keberhasilan atau kegagalan suatu perusahaan. Meningkatnya intensitas persaingan dari pesaing menuntut perusahaan untuk selalu memperhatikan kebutuhan dan keinginan konsumen serta berusaha memenuhi harapan konsumen dengan cara memberikan pelayanan yang lebih memuaskan dari pada yang dilakukan oleh pesaing. Dengan demikian, hanya perusahaan yang berkualitas yang dapat bersaing dan menguasai pasar. Salah satu usaha yang sedang berkembang saat ini adalah usaha retail dalam bentuk minimarket. Adanya konsep retail dalam bentuk minimarket telah diperkenalkan ke negara-negara berkembang yang konsumennya belum mempunyai pengalaman berbelanja di toko yang berskala besar dengan jenis produk yang beragam namun pada tingkat harga yang relatif rendah. Adanya konsep baru pada dunia retail umumnya dapat menarik perhatian konsumen karena menawarkan sesuatu yang baru dan dapat menimbulkan rasa senang dalam bebelanja. 
Perkembangan bisnis retail di Indonesia dapat dikatakan cukup pesat akhir-akhir ini,terutama retail modern dalam semua variasi jenisnya. Beberapa faktor pendukung perkembangan usaha retail modern diantaranya adalah cukup terbukanya peluang pasar, perkembangan usaha manufaktur yang akan memasok produknya ke retailer (peretail), dan upaya pemerintah untuk mendorong pertumbuhan ekonomi dengan cara salah satunya mengembangkan bisnis retail. Salah satu indikator berkembangnya bisnis retail adalah loyalitas konsumen, Loyalitas konsumen merupakan hal yang penting dalam kegiatan suatu usaha retail. Dengan adanya tingkat loyalitas konsumen yang tinggi, konsumen akan melakukan pembelian secara terus - menerus dan membawa dampak yang menguntungkan bagi perusahaan retail.

Untuk meningkatkan loyalitas konsumen, maka cara yang bisa digunakan adalah meningkatkan persepsi baik konsumen terhadap perusahaan. Secara garis besar perusahaan ingin mengikat konsumen selama-lamanya untuk perencanaan jangka panjang, namun bukan hanya persepsi konsumen yang mempengaruhi pembelian ulang, kualitas dan ketahanan produk yang dijual juga sangat berpengaruh dalam keputusan konsumen melakukan pembelian ulang (Amirullah. 2002)

Penelitian yang dilakukan oleh Ambriansyah (2011) dengan judul penelitian "Analisis persepsi konsumen terhadap keputusan pembelian produk Blackberry.(studi kasus karyawan PT.Pusri Palembang)" menunjukan bahwa ketahanan suatu produk akan mempengaruhi persepsi konsumen untuk membelinya kembali.

Peneltian yang dilakukan oleh Wahya Dewi Urip (2008) dengan judul penelitian "Pengaruh motivasi, persepsi dan sikap konsumen terhadap keputusan pembelian sepeda motor merek "Honda" di kawasan Surabaya barat" menunjukan bahwa Motivasi diri akan mempengaruhi seseorang konsumen dalam melakukan pembelian, misalnya penilaian terhadap kualitas harga, kenyamanan peran persepsi konsumen juga akan mempengaruhi pula terhadap keputusan pembelian

Menurut (Yriyono sigit. 2006) Faktor pendukung untuk menumbuhkan persepsi konsumen terhadap perusahaan adalah : (1) Lokasi gerai yang strategis dan mudah di jangkau

1. Sifat dan kualitas barang yang dijual

2. Fasilitas yang memadai

3. Iklan dan promosi

4. Personil penjualan/pelayanan yang baik

5. Harga yang bersaing

Salah satu contoh bisnis retail modern yang berkembang pesat adalah indomaret, yaitu bisnis retail yang didirikan oleh PT. INDOMARCO PRISMATAMA salah satu anak perusahaan Salim Group, tahun 1988 perusahaan ini membuka gerai pertama di ancol, Jakarta utara, perusahaan ini terus berkembang hingga pada awal tahun 2016 jumlah gerai indomaret sebanyak 12.100 gerai, dengan rincian $60 \%$ gerai adalah milik sendiri dan $40 \%$ adalah waralaba milik masyarakat. Perusahaan ini mempunyai Motto "mudah dan hemat" (http://Indomaret.co.id)

Di Provinsi Jambi terdapat puluhan gerai indomaret yang tersebar di Kota Jambi sampai ke kabupaten dan kecamatan yang ada di Provinsi Jambi, salah 
satunya berada di Kecamatan Sungai Bahar. Sejalan dengan judul penelitian ini, maka dilakukan observasi awal untuk mengetahui kondisi secara umum mengenai gerai indomaret yang ada di Kecamatan Sungai Bahar, berdasarkan hasil observasi jumlah karyawan sebanyak 5 orang didalam 1 gerai dengan rincian, 1 orang kepala gerai, 1 orang asisten kepala gerai, 1 orang kasir, 1 orang Merchandieser, dan 1 orang pramuniaga, dengan rata-rata konsumen 100 konsumen / hari. Produk yang ada didalam gerai bermacam-macam jenisnya mulai dari perlengkapan dapur, mandi, bayi, makanan, minuman, dll.

Ukuran keberhasilan indomaret adalah bagaimana persepsi konsumen dapat meningkatkan kepercayaan terhadap indomaret sehingga konsumen mempunyai keinginan membeli yang sangat kuat.

Berdasarkan hal tersebut di atas dan menyadari akan pentingnya persepsi konsumen, sehingga penulis ingin mengetahui pengaruh persepsi konsumen terhadap keputusan pembelian ulang pada indomaret Sungai Bahar.

\section{METODE PENELITIAN}

Penelitian ini menggunakan metode survei, wawancara dan penyebaran quesioner dengan melakukan penelitian langsung terhadap pihak-pihak tertentu termasuk komponen-komponen yang berhubungan dengan kegiatan penelitian yang dilakukan.

Analisis yang digunakan adalah analisis regresi linear sederhana, yaitu analisis untuk mengukur pengaruh variabel independen terhadap variabel depedenden.

Populasi dalam penelitian ini adalah seluruh konsumen yang datang ke gerai indomaret Sungai Bahar, sedangkan sampel penelitian sebanyak 80 konsumen, dengan tehnik pengambilan sampel secara random sampling. .(Sugiyono 2006)

\section{HASIL DAN PEMBAHASAN}

Tabel 1. Distribusi Responden yang datang ke Indomaret Sungai Bahar berdasarkan Jenis Kelamin

\begin{tabular}{ccc}
\hline Jenis Kelamin & Jumlah Responden & Persentase (\%) \\
\hline Laki-laki & 42 Orang & 52,5 \\
Perempuan & 38 Orang & 47,5 \\
Jumlah & 80 Orang & 100 \\
\hline
\end{tabular}

Dari Tabel 1 di atas diperoleh gambaran bahwa jumlah pengunjung indomaret sungai bahar lebih banyak pengunjung laki-laki dengan 42 konsumen dan pengunjung perempuan lebih rendah yaitu 38 konsumen. Hal ini berarti menunjukkan keputusan pembelian di Indomaret lebih banyak dilakukan laki-laki dari pada perempuan.

Tabel 2. Distribusi Responden yang datang ke Indomaret Sungai Bahar berdasarkan Umur

\begin{tabular}{ccc}
\hline Umur (Tahun) & Jumlah Responden & Persentase (\%) \\
\hline $17-25$ & 47 Oarang & 58,75
\end{tabular}




$\begin{array}{ccc}26-30 & 20 \text { Orang } & 25 \\ 31-35 & 9 \text { Orang } & 11,25 \\ 36-40 & 4 \text { Orang } & 5 \\ >40 & - & - \\ \text { Jumlah } & 80 \text { Orang } & 100 \%\end{array}$

Dari Tabel 2 di atas menunjukkan bahwa responden yang berumur 17-25 tahun merupakan kelompok responden yang terbesar dengan jumlah 47 orang atau sebanyak 58,75\%, kemudian responden yang berumur 26-30 tahun dengan jumlah responden 20 orang atau sebanyak $25 \%$, responden yang berumur 31-35 tahun dengan jumlah responden 9 orang atau $11,25 \%$ dan responden yang berusia 36-40 tahun dengan jumlah responden 4 orang atau sebanyak 5\%. Hal ini menunjukan bahwa para remaja pada usia produktif, yaitu antara 17-30 tahun mempunyai hasrat pembelian ulang yang tinggi ke indomaret sungai bahar.

Tabel 3. Distribusi Responden yang datang ke Indomaret Sungai Bahar berdasarkan Pendidikan Terakhir

\begin{tabular}{ccc}
\hline Pendidikan Terakhir & Jumlah Responden & Persentase \\
\hline SD & - & - \\
SMP & 1 Orang & $1,25 \%$ \\
SMA/SMK & 32 Orang & $40 \%$ \\
Diploma & 16 Orang & $20 \%$ \\
S1 & 26 Orang & $32,5 \%$ \\
S2 & 5 Orang & $6,25 \%$ \\
Jumlah & 80 Orang & $100 \%$ \\
\hline
\end{tabular}

Dari Tabel 3 di atas menunjukkan bahwa responden yang pendidikan terakhirnya SMA/SMK adalah yg paling dominan yaitu sebanyak 32 orang atau sebesar 40\%, kemudian diikuti dengan pendidikan terakhir S1 sebayak 26 orang atau sebesar 32,5\%, Diploma sebayak 16 orang atau sebesar 20\%, S2 sebayak 5 orang atau sebesar 6,25\%, dan SMP sebayak 1 orang atau sebesar 1,25\%.

Tabel 4. Distribusi Responden yang datang ke Indomaret Sungai Bahar berdasarkan Pekerjaan

\begin{tabular}{ccc}
\hline Pekerjaan & Jumlah Responden & Persentase (\%) \\
\hline Pelajar & 28 Orang & 35 \\
Mahasiswa & 1 Orang & 1,25 \\
Pegawai Negeri Sipil & 18 Orang & 22,5 \\
Pegawai Swasta & 24 Orang & 30 \\
Wiraswasta & 6 Orang & 7,5 \\
Lain-lain & 3 Orang & 3,75 \\
Jumlah & 80 Orang & $100 \%$ \\
\hline
\end{tabular}

Dari Tabel 4 di atas dapat dilihat bahwa dari 80 responden yang melakukan transaksi di Indomaret sungai bahar, jumlah yang yang paling banyak adalah pelajar dengan 35\% atau tepatnya sebanyak 28 orang konsumen, pegawai swasta sebanyak $30 \%$ atau 24 orang konsumen, pegawai negeri sipil sebanyak 
$22,5 \%$ atau 18 orang konsumen, wiraswasta 7,5\% atau 6 orang konsumen, lainlain $3,75 \%$ atau 3 orang dan mahasiswa $1,25 \%$ atau 1 orang.

Tabel 5. Distribusi Responden yang datang ke Indomaret Sungai Bahar berdasarkan jumlah Pendapatan

\begin{tabular}{ccc}
\hline Pendapatan/ Bulan (Juta) & Responden & Persentase (\%) \\
\hline$*<$ Rp. 5.00.000 & 1 Orang & 1,25 \\
Rp. 1 s/d Rp1.5 & 29 Orang & 36,2 \\
Rp1.5 s/d Rp 2.5 & 27 Orang & 33,75 \\
Rp 2.5s/d Rp 3.5 & 21 Orang & 26,25 \\
Rp 3.5s/d Rp 4.5 & 2 Orang & 2,5 \\
$>$ Rp 4.5 & - & - \\
Jumlah & 80 Orang & 100 \\
\hline
\end{tabular}

Dari Tabel 5 di atas menunjukkan bahwa responden yang memiliki pendapatan/bulan Rp. 500.000,- s/d Rp1.500.000,- sebanyak 29 orang atau sebesar 36,25\%, responden yang mempunyai penghasilan antara Rp 1.500.000,s/d Rp 2.500.000,- sebanyak 27 orang atau sebesar 33,75\%, responden yang mempunyai penghasilan Rp 2.500.000,- s/d Rp 3.500.000,- sebanyak 21 atau sebesar 26,25\%, kemudian di ikuti oleh responden yang memiliki penghasilan Rp 3.500.000,- s/d Rp 4.500.000,- sebanyak 2 orang atau sebanyak 2,5\% dan responden yang memiliki penghasilan < Rp. 5.00.000,- sebanyak 1 orang atau sebanyak $1,25 \%$. Dari penjelasan diatas bisa diambil kesimpulan bahwa yang mempunyai keinginan membeli kembali di indomaret sungai bahara adalah konsumen yang berpendapatan Rp.1.5,000,000 - Rp. 3.5,000,000.

Tabel 6. Hasil Quesioner Variabel Persepsi Konsumen (X)

\begin{tabular}{|c|c|c|c|c|c|c|c|}
\hline \multirow{2}{*}{ No } & \multirow{2}{*}{ Indikator } & \multicolumn{5}{|c|}{ Skor } & \multirow{2}{*}{ Rata - rata } \\
\hline & & SS & S & $\mathrm{RR}$ & TS & STS & \\
\hline \multirow{2}{*}{1.} & \multirow{2}{*}{ Lokasi yang strategis } & 25 & 46 & 9 & 0 & 0 & \multirow{2}{*}{4,20} \\
\hline & & $31,2 \%$ & $57,5 \%$ & $11,2 \%$ & $0 \%$ & $0 \%$ & \\
\hline \multirow{2}{*}{2.} & Penyediaan lokasi parkir & 9 & 55 & 16 & 0 & 0 & \multirow{2}{*}{3,91} \\
\hline & yang aman dan luas & $11,2 \%$ & $68,7 \%$ & $20 \%$ & $0 \%$ & $0 \%$ & \\
\hline \multirow{2}{*}{3.} & Lokasi dekat dengan & 16 & 49 & 14 & 1 & 0 & \multirow{2}{*}{4,00} \\
\hline & rumah warga & $20 \%$ & $61,2 \%$ & $17,5 \%$ & $1,2 \%$ & $0 \%$ & \\
\hline \multirow{2}{*}{4.} & Tersedianya ATM, AC, & 18 & 38 & 22 & 2 & 0 & \multirow{2}{*}{3,90} \\
\hline & dan parkir gratis & $22,5 \%$ & $47,5 \%$ & $27,5 \%$ & $2,5 \%$ & $0 \%$ & \\
\hline \multirow{2}{*}{5.} & Penyediaan keranjang & 19 & 31 & 30 & 0 & 0 & \multirow{2}{*}{3,86} \\
\hline & yang cukup & $23,7 \%$ & $38,7 \%$ & $37,5 \%$ & $0 \%$ & $0 \%$ & \\
\hline \multirow{2}{*}{6.} & Keramahan pramuniaga & 3 & 47 & 24 & 6 & 0 & \multirow{2}{*}{3,59} \\
\hline & 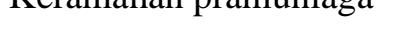 & $3,7 \%$ & $58,7 \%$ & $30 \%$ & $7,5 \%$ & $0 \%$ & \\
\hline \multirow{2}{*}{7.} & Pelayanan pramuniaga & 8 & 39 & 33 & 0 & 0 & \multirow{2}{*}{3,69} \\
\hline & & $10 \%$ & $48,7 \%$ & $41,2 \%$ & $0 \%$ & $0 \%$ & \\
\hline \multirow{2}{*}{8.} & Pakaian pramuniaga & 14 & 38 & 24 & 4 & 0 & \multirow{2}{*}{3,78} \\
\hline & & $17,5 \%$ & $47,5 \%$ & $30 \%$ & $5 \%$ & $0 \%$ & \\
\hline \multirow{2}{*}{9.} & Potongan harga & 7 & 22 & 41 & 10 & 0 & \multirow{2}{*}{3,33} \\
\hline & & $8,7 \%$ & $27,5 \%$ & $51,2 \%$ & $12,5 \%$ & $0 \%$ & \\
\hline \multirow{3}{*}{10} & Sesuai dengan harga & 3 & 27 & 34 & 15 & 1 & 3.20 \\
\hline & pas & $7 \%$ & $33,7 \%$ & $42,5 \%$ & $18,7 \%$ & $1,2 \%$ & \\
\hline & \multicolumn{6}{|c|}{ Rata-rata } & 3,75 \\
\hline
\end{tabular}


Dalam variabel persepsi konsumen di atas, untuk memudahkan dalam perhitungan hasil kuesioner, maka akan dibagi dalam 10 indikator.

Dari Tabel 6 di atas diketahui bahwa rata-rata keseluruhan dari indikator mengenai persepsi konsumen adalah 3,75. Hal ini menunjukan bahwa responden setuju mengenai indikator persepsi konsumen. Untuk rata-rata setiap pernyataan, nilai paling tinggi dan responden sangat setuju didapat pada indikator pertama sebesar 4,20 yaitu lokasi yang strategis menjadi pertimbangan dalam melakukan pembelian. Lokasi dalam memilih tempat belanja yang diseleksi konsumen adalah perjalanan dan kestrategisan tempat dan kemudahan untuk mencapai tempat tersebut selain itu kemudahan dalam memarkirkan kendaraan, kelancaran arus lalu lintas turut menjadi pertimbangan konsumen, hal ini menunjukan bahwa lokasi Indomaret yang strategis karena dekat dengan pusat keramain dan dekat dengan pemukiman konsumen. Sedangkan untuk nilai terendah didapat pada indicator kesepuluh yaitu sesuai harga pasar saat ini, mengenai konsumen membeli di Indomaret karena harganya sesuai dengan harga pasar saat ini responden memberi nilai cukup sebesar 3,20. Pentingnya harga sebagai determinan atau penentu untuk berlangganan di toko atau perusahaan jasa bervariasi menurut jenis produk. Harga adalah variabel penuh resiko untuk dijadikan azas dalam pengembangan program pemasaran, karena harga sebagai salah satu daya tarik pembeli, hal ini menunjukan bahwa harga bukanlah kendala bagi konsumen Indomaret dikarenakan harga-harga produk di Indomaret terjangkau semua kalangan.

Pelayanan pramuniaga juga menjadi aspek penting agar konsumen datang kembali untuk belanja, dengan nilai 3,69, selain itu penampilan dari segi berpakaian para pramuniaga dan pegawai indoamret juga menjadi tolak ukur konsumen dalam hal persepsi konsumen.

Dengan demikian diharapkan Indomaret dapat lebih memperhatikan aspek persepsi konsumen sebagai landasan dalam mempertahankan dan memperbaiki pelayanan yang diberikan kepada konsumen dan pelanggan dengan memanfaatkan lebih lanjut aspek dari variabel persepsi pembelian tersebut.

Tabel 7. Hasil Quesioner Variabel Keputusan Pembelian Ulang (Y)

\begin{tabular}{|c|c|c|c|c|c|c|c|}
\hline \multirow{2}{*}{ No. } & \multirow{2}{*}{ Indikator } & \multicolumn{5}{|c|}{ Skor } & \multirow{2}{*}{ Rata - rata } \\
\hline & & SS & S & RR & $\mathrm{TS}$ & STS & \\
\hline \multirow[b]{2}{*}{11} & Tersedianya & 22 & 43 & 13 & 2 & 0 & \multirow[b]{2}{*}{4,06} \\
\hline & $\begin{array}{l}\text { produk yang lengkap } \\
\text { dan beragam }\end{array}$ & $27,5 \%$ & $53,8 \%$ & $16,3 \%$ & $2,5 \%$ & $0 \%$ & \\
\hline 12. & $\begin{array}{l}\text { Menyukai merek } \\
\text { produk }\end{array}$ & $\begin{array}{c}5 \\
6,3 \%\end{array}$ & $\begin{array}{c}40 \\
50 \%\end{array}$ & $\begin{array}{c}31 \\
38,8 \%\end{array}$ & $\begin{array}{c}4 \\
5 \%\end{array}$ & $\begin{array}{c}0 \\
0 \%\end{array}$ & 3,58 \\
\hline 13. & $\begin{array}{l}\text { Kualitas produk yang } \\
\text { baik }\end{array}$ & $\begin{array}{c}7 \\
8,8 \%\end{array}$ & $\begin{array}{c}36 \\
45 \%\end{array}$ & $\begin{array}{c}37 \\
46,3 \%\end{array}$ & $\begin{array}{c}0 \\
0 \%\end{array}$ & $\begin{array}{c}0 \\
0 \%\end{array}$ & 3,63 \\
\hline 14. & $\begin{array}{l}\text { Prodak telah di uji } \\
\text { BPOM dan tidak ada } \\
\text { prodak } \\
\text { kadaluarsa }\end{array}$ & $16,3 \%$ & $33,8 \%$ & $45 \%$ & $5 \%$ & $0 \%$ & 3,61 \\
\hline 15. & $\begin{array}{l}\text { Dilengkapi dengan } \\
\text { fasilitas kartu kredit }\end{array}$ & $\begin{array}{c}7 \\
8,8 \%\end{array}$ & $\begin{array}{c}46 \\
57,5 \%\end{array}$ & $\begin{array}{c}26 \\
32,5 \%\end{array}$ & $\begin{array}{c}1 \\
1,3 \%\end{array}$ & $\begin{array}{c}0 \\
0 \%\end{array}$ & 3,74 \\
\hline \multirow[t]{2}{*}{16.} & $\begin{array}{l}\text { Dilengkapi dengan } \\
\text { kartu anggota }\end{array}$ & $\begin{array}{c}14 \\
17,5 \%\end{array}$ & $\begin{array}{c}41 \\
51,3 \%\end{array}$ & $\begin{array}{c}25 \\
31,3 \%\end{array}$ & $\begin{array}{c}0 \\
0 \%\end{array}$ & $\begin{array}{c}0 \\
0 \%\end{array}$ & 3,86 \\
\hline & \multicolumn{6}{|c|}{ Rata-rata } & 3,75 \\
\hline
\end{tabular}


Dari Tabel 7 di atas diketahui bahwa rata-rata keseluruhan dari pernyataan mengenai keputusan pembelian ulang adalah 3,75. Hal ini menunjukan bahwa responden setuju mengenai pernyataan keputusan pembelian ulang. Untuk rata-rata setiap pernyataan, nilai paling tinggi didapat pada pernyataan pertama sebesar 4,06 yaitu mengenai tersedianya merek produk yang lengkap dan beragam yang menjadi pertimbangan responden dalam pembelian di Indomaret. Hal ini menunjukan bahwa merek suatu produk itu mempengaruhi persepsi konsumen akan kualitas dari produk tersebut.

Sedangkan untuk nilai terendah didapat pada pernyataan kedua sebesar 3,58 yaitu mengenai menyukai merek poduk Indomaret, untuk produk-produk yang ada di Indomaret ada sebagian yang bermerek Indomaret hal ini membuat responden memiliki penilaian yang cukup atau hanya sedikit mempengaruhi keputusan pembelian karena di Indomaret banyak merek-merak lain yang membuat konsumen mempertimbangkan membeli produk yang terbaik.

Tabel 8. Hasil Uji Validitas Variabel persepsi Konsumen (Variabel X)

\begin{tabular}{ccc}
\hline Pernyataan & Nilai ritung $_{\text {r }}$ & Kesimpulan \\
\hline Indikator 1 & 0,435 & Valid \\
Indikator 2 & 0,565 & Valid \\
Indikator 3 & 0,393 & Valid \\
Indikator 4 & 0,543 & Valid \\
Indikator 5 & 0,742 & Valid \\
Indikator 6 & 0,481 & Valid \\
Indikator 7 & 0,579 & Valid \\
Indikator 8 & 0,372 & Valid \\
Indikator 9 & 0,426 & Valid \\
Indikator 10 & 0,617 & Valid \\
\hline
\end{tabular}

Suatu kuesioner dikatakan valid jika pernyataan kuesioner mampu untuk mengungkapkan sesuatu yang akan diukur oleh kuesioner tersebut. Kriteria instrumen valid apabila nilai $r$ hitung $>r$ tabel. Dalam hal ini $\mathrm{df}=30-2=28$ dan nilai probabilitas korelasi taraf signifikan $(\alpha)$ sebesar $0,05(5 \%)$ pada tabel, maka diperoleh angka $r_{\text {tabel }}=0,361$. Berdasarkan hasil uji validitas pada tabel 8 di atas variabel persepsi konsumen menggunakan SPSS versi 16.0 semua variabel persepsi konsumen dinyatakan valid karena mempunyai koefisien korelasi yang lebih besar dari $r_{\text {tabel }}=0,361$.

Tabel 9. Hasil Uji Validitas Variabel Keputusan Pembelian Ulang (Variabel Y)

\begin{tabular}{ccc}
\hline Pernyataan & Nilai ritung $_{\text {}}$ & Kesimpulan \\
\hline Indikator 11 & 0,501 & Valid \\
Indikator 12 & 0,422 & Valid \\
Indikator 13 & 0,701 & Valid \\
Indikator 14 & 0,604 & Valid \\
Indikator 15 & 0,499 & Valid \\
Indikator 16 & 0,784 & Valid \\
\hline
\end{tabular}


Berdasarkan hasil uji validitas variabel persepsi konsumen menggunakan SPSS versi 16.0 semua variabel keputusan pembelian dinyatakan valid karena mempunyai koefisien korelasi yang lebih besar dari $r_{\text {tabel }}=0,361$.

Tabel 9. Hasil Uji Reliabilitas

\begin{tabular}{clcc}
\hline No. & \multicolumn{1}{c}{ Variabel } & Cronbach Alpha & Kesimpulan \\
\hline 1. & X (Persepsi Konsumen) & 0,673 & Reliabel \\
2. & Y (Keputusan Pembelian) & 0,617 & Reliabel \\
\hline
\end{tabular}

Hasil tersebut menunjukkan bahwa semua variabel mempunyai Cronbach Alpha yang lebih besar yaitu di atas 0,60 sehingga dapat dikatakan pengukur variabel $\mathrm{X}$ dan variabel $\mathrm{Y}$ dari kuesioner adalah reliabel sehingga untuk selanjutnya item-item pada masing-masing konsep variabel tersebut layak digunakan sebagai alat ukur.

Tabel 10. Hasil Regresi Linier Sederhana

Coefficients $^{\mathbf{a}}$

\begin{tabular}{|c|c|c|c|}
\hline \multirow{2}{*}{ Model } & \multicolumn{2}{|c|}{ Unstandardized Coefficients } & Standardized \\
\hline & $\mathbf{B}$ & Std. Error & Beta \\
\hline 1 (Constant) & 5.333 & 2.275 & \\
\hline Persepsi Konsumen & .458 & .061 & .650 \\
\hline
\end{tabular}

a. Dependent Variable: Keputusan Pembelian

Dari hasil tersebut apabila ditulis dalam bentuk persamaan regresinya adalah sebagai berikut :

$$
\mathrm{Y}=5,333+0,458 \mathrm{X}
$$

\section{Konstanta}

$$
: 5,333
$$

Persepsi konsumen $(\mathrm{X}) \quad: 0,458$

Hasil analisis ini terbentuk dalam persamaan regresi sederhana dan di interpretasikan sebagai berikut:

$\mathrm{a}=5,333$ adalah konstanta, artinya jika persepsi konsumen $(\mathrm{X})$ nilainya 0 , maka keputusan pembelian (Y) adalah sebesar 5,33.

Koefisien regresi $\mathrm{b}=0,458$ menyatakan bahwa setiap penambahan persepsi konsumen (X) sebesar 1, maka keputusan pembelian (Y) akan meningkat sebesar 0,458 .

Tabel 11. Uji Koefisien Regresi Secara Parsial (Uji t)

\begin{tabular}{|rl|r|r|}
\hline \multicolumn{2}{|c|}{ Model } & \multicolumn{1}{|c|}{ T } & \multicolumn{1}{c|}{ Sig. } \\
\hline \multirow{2}{*}{1} & - & 2.344 & .022 \\
& Persepsi Konsumen & 7.563 & .000 \\
\hline
\end{tabular}

Pengaruh Persepsi Konsumen terhadap Keputusan Pembelian Ulang pada Indomaret Kecamatan Sungai Bahar 
Dari hasil regresi Uji t tersebut di tarik dua kesimpulan yaitu :

Ho : $\mathrm{b} 1=0$, berarti tidak ada pengaruh secara signifikan antara persepsi konsumen terhadap keputusan pembelian ulang pada Indomaret.

Ha : $b 1 \neq 0$, berarti ada pengaruh secara signifikan antara persepsi konsumen terhadap keputusan pembelian ulang pada Indomaret.

Pengaruh persepsi konsumen terhadap keputusan pembelian ditunjukkan dengan nilai thitung sebesar 7,563, dengan nilai signifikansinya sebesar $0,000<\alpha=$ 0,05 sehingga dapat dikatakan ada pengaruh yang signifikan antara pengaruh persepsi konsumen terhadap keputusan pembelian ulang pada Indomaret.

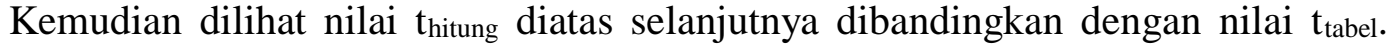
Untuk mendapatkan nilai $t_{\text {tabel}}$, maka dilakukan uji 2 pihak yaitu $\mathrm{dk}=\mathrm{n}-2 \mathrm{dan} \mathrm{dk}$ $=80-2=78$, bila taraf kesalahan ditetapkan sebesar 0,05 (5\%) maka diperoleh $\mathrm{t}_{\text {tabel }}=1,665$. Karena nilai $\mathrm{t}_{\text {hitung }}>\mathrm{t}_{\text {tabel }}$ berarti Ha diterima dan Ho ditolak yang berarti ada pengaruh secara signifikan antara persepsi konsumen terhadap keputusan pembelian ulang pada Indomaret.

Tabel 12. Koefisien Determinasi $\left(\mathbf{R}^{2}\right)$

Model Summary

\begin{tabular}{|l|r|r|r|r|}
\hline Model & R & R Square & \multicolumn{1}{|c|}{$\begin{array}{c}\text { Adjusted R } \\
\text { Square }\end{array}$} & $\begin{array}{c}\text { Std. Error of the } \\
\text { Estimate }\end{array}$ \\
\hline 1 & $.650^{\mathrm{a}}$ & .423 & .416 & 1.741 \\
\hline
\end{tabular}

a. Predictors: (Constant), Persepsi Konsumen

Hasil perhitungan dapat diketahui bahwa koefisien determinasi diperoleh $\mathrm{R}^{2}(\mathrm{R}$ Square) sebesar 0,423 atau 42,3\%. Hal ini menunjukkan bahwa persentase sumbangan pengaruh variabel persepsi konsumen terhadap keputusan pembelian ulang sebesar 42,3\%. Atau variasi variabel persepsi konsumen mampu menjelaskan sebesar $42,3 \%$ variasi variabel keputusan pembelian ulang. Sedangkan sisanya sebesar $57,7 \%$ di pengaruhi atau dijelaskan oleh variabel lain yang tidak dimasukkan dalam model penelitian ini.

\section{SIMPULAN}

Berdasarkan hasil penelitian dan pembahasan persepsi konsumen yang mempengaruhi keputusan pembelian ulang pada Indomaret Kecamatan Sungai Bahar. Maka dapat di tarik kesimpulan sebagai berikut:

1. Hasil penelitian ini menunjukkan persepsi konsumen berpengaruh signifikan terhadap keputusan pembelian ulang dimana nilai signifikannnya $0,000>\alpha=$ 0,05 dan nilai thitung $>t_{\text {tabel }}(7,563>1,665)$.

2. Besarnya pengaruh persepsi konsumen terhadap keputusan pembelian ulang sebesar $42,3 \%$ atau persepsi konsumen mampu menjelaskan sebesar $42,3 \%$ keputusan pembelian, sedangkan $57,7 \%$ di pengaruhi atau dijelaskan oleh variabel lain yang tidak dimasukkan dalam model penelitian ini.

\section{DAFTAR PUSTAKA}

Adisetiawan, R., dan Hasminidiarty, 2012, Analisis Pengaruh Variabel-Variabel Makroekonomi dan Mikroekonomi Terhadap Risiko Investasi Saham, Jurnal Ekonomi, 26(2), 159-174 
Adisetiawan, R., 2018, Kausalitas Ekonomi Makro dan Global Terhadap Pasar Modal Indonesia, Ekonomis: Journal of Economics and Business, 2(1), 1017

Ambriansyah. 2011. Analisis Persepsi Konsumen Terhadap Keputusan Pembelian Produk Blackberry (Studi Kasus Karyawan PT. Pusri Palembang)

Amirullah. 2002. Perilaku Konsumen. Yogyakarta: Penerbit Graha Ilmu.

Arikunto, Suharmisi. 1998. Prosedur Penelitian Suatu Pendekatan Paktek. Jakarta: Rineka Cipta

Indomaret, 2012. Indomaret targetkan 1000 gerai baru. (http://Indomaret.co.id Diakses 4 oktober 2016).

Sigit, Yriyono. 2006. Sukses Terpadu Bisnis Ritel. Jakarta: PT Elek Media Komputindo Kelompok Grmaedia.

Sugiyono. 2006. Statistika untuk Penelitian. Bandung: Alfabeta.

Wahyu, Dewi, Urip. 2008. Pengaruh Motivasi, Persepsi dan Sikap Konsumen

Terhadap Keputusan Pembelian Sepeda Motor Merek "Honda" di Kawasan Surabaya Barat.

2010. Metode Penelitian Bisnis. Bandung: Alfabeta

(www.aprindo.org) di akses tanggal 04 oktober 2016. 